\title{
Cold Radial Extrusion of a Gear-Like Element with Flow Relief Opening
}

\author{
Plavka SKAKUN, Robert LENGYEL, Sebastian BALOŠ, Dejan MOVRIN, Mladomir MILUTINOVIĆ
}

\begin{abstract}
When divided material flow is enabled during extrusion process, the required forming load is lower compared to a conventional process. The reduction of forming load leads to higher quality of extruded part and longer tool life. One way to achieve divided material flow is the application of a relief opening, either in the billet or in the tool. In this paper, theoretical solution based upon the Upper bound theorem was used to determine the forming load for radial extrusion of a gear-like element with straight parallel flank profile. Two possible positions of relief openings were analysed - in the centre of the billet and in the centre of the punch. Theoretical solution was compared to experimental results. Material of billets was Al 99,5. Comparison between theoretical and experimental values of the forming load showed fairly good agreement. Further development of the proposed theoretical solution should lead to better process description and more accurate value of the forming load.
\end{abstract}

Keywords: extrusion; gear-like element; relief opening; upper bound

\section{INTRODUCTION}

Although cold extrusion processes have many advantages such as material saving, high productivity, high strength and quality of extruded part it is burdened by high forming loads which affects quality of the extruded part and causes high tool wear. This is especially evident at the final stage of radial extrusion process, when the corner filling phenomena occur. In that stage workpiece reaches its final shape and small die volume remains unfilled causing sharp increase in forming load.

One of the solutions to this problem is to design a process which would enable divided flow of material and load reduction. This can be achieved in different ways: using billet or die with central opening, by varying shape of punch and/or die, or by varying the tool design.

Ogha and Kondo [1] were among the first to apply flow relief openings in order to achieve divided flow of material which would lead to reduction of forming load and complete die filling. Two ways to accomplish that task were proposed, with the openings in the upper and lower die (relief axis) and with the central opening in the billet (relief hole). Theoretical solution was confirmed by experimental study [2].This principle was also applied to gear forging $[3,4]$.

Effects of billet geometry on the process of cold forging of helical gears utilizing the relief hole principle were analysed by Feng at al. [5]. Through FE simulation billet geometry was optimized to meet requirement of lower forming load and better deformation uniformity.

Technology for spur gear forging which includes two steps in forging process was proposed by Choi and Choi [6]. The part got a concave shape at the bottom surface in the first step, which took the role of the inside relief in the second step, thus lowering the forging load. Analysis of spur gear forging, as well as the trochoidal gear with inside relief, was performed by the Upper bound theorem [7, 8].

Improvement of die filling conditions by die shape changing in spur gear closed die forging, was analysed by $\mathrm{Hu}$ at al. [9]. Experimental and numerical results showed that the scheme which employed the wave form end surface of the punch and bottom surface of the die, yielded better results than conventional one, due to better filling of die corners.
Cai at al. [10] considered different tool design in warm gear forging, investigating how it influences metal flow and load requirements. Similar tool was used for Bi-metal gears forging [11].

Zuo at al. [12] further developed the idea of alternative die design and chamfered punch. They found that different sizes of relief-cavity could reduce the resistance of material to flow, which requires optimization of relief cavity size to control material waste.

Behrens et al. $[13,14]$ applied flow relief opening in the tool for hot extrusion of gears. The role of relief hole was to compensate for the excess material of the billet.

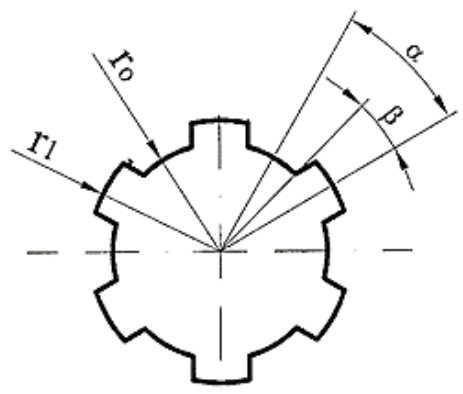

Figure 1 Geometry of gear-like element with straight parallel flank profile

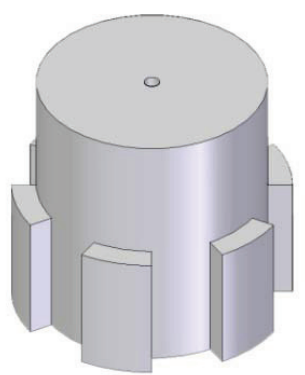

Figure 2 The $\mathrm{OB}$ model - flow relief opening in the centre of the billet

Application of flow relief openings was most frequently analysed in the processes of forging or extrusion of various kinds of gears and splines, usually with the relief opening in the billet. In the study presented in this paper theoretical analysis of radial extrusion process of a gearlike element with straight parallel flank profile (Fig. 1) is proposed using the relief opening principle. Two positions of flow relief opening were considered: in the centre of the billet, the OB model (Fig. 2) and in the centre of the punch, 
the OP model (Fig. 3). Theoretical analysis was based upon the Upper bound theorem. Forming load was obtained by theoretical solution and compared with experimental results.

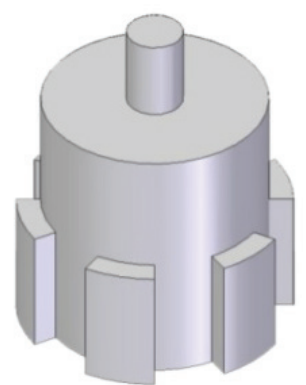

Figure 3 The OP model - flow relief opening in the centre of the punch

\section{UPPER BOUND SOLUTION}

Total power of deformation, $\dot{W}_{t}$, was approximated using expression based on the Upper bound theorem:

$$
\begin{aligned}
& \dot{W}_{t}=\dot{W}_{d}+\dot{W}_{s}+\dot{W}_{f}=\frac{2}{\sqrt{3}} \sigma_{e} \int_{V} \sqrt{\frac{1}{2} \dot{\varepsilon}_{i j} \dot{\varepsilon}_{i j}} d V+ \\
& +\int_{A_{s}} \tau_{s}|\Delta v| d A_{s}+\int_{A_{f}} \tau_{f}|\Delta v| d A_{f}
\end{aligned}
$$

The first component, $\dot{W}_{d}$, represents the power of internal deformation, the second component, $\dot{W}_{s}$, is shear loss, while $\dot{W}_{f}$ represents friction loss.

To determine all components of Eq. (1) it is necessary to assume kinematically admissible velocity field within the workpiece. The forming body has to be divided into zones based on the predicted material flow during extrusion process and velocity field components have to be assumed for each zone.

When the relief opening is present in an extrusion process, the divided material flow occurs. The neutral surface, where the material changes flow direction, is formed within a workpiece volume and generally the material flows in such a way as to fill both the die cavity and relief opening. Position of the neutral surface is determined by the neutral radius, $r_{n}$.

For the OB model, workpiece was divided into 5 zones for the general case of material flow (Fig. 4). Boundary cases had fewer zones and could be derived from the general one, as well as the conventional extrusion, when there is no opening in the billet or in the punch. For each zone, components of velocity field were predicted to meet incompressibility law and boundary conditions.

In the zone 1, components of the velocity field are:

$v_{z}=-\frac{v_{0}}{H} z \quad v_{\theta}=0 \quad v_{r}=-\frac{v_{0}}{2 H} \frac{r^{2}-r_{n}^{2}}{r}$

In the zone 2, material moves as a rigid body, thus only the component in the axial direction exists:

$$
v_{z}=-v_{0} \quad v_{\theta}=0 \quad v_{r}=0
$$

In the zone 3, the radial component is zero:

$$
v_{z}=-\frac{v_{0}}{h_{t}} z \quad v_{\theta}=-\frac{v_{0}}{h_{t}} r(\alpha-\theta) \quad v_{r}=0
$$

Following expressions are assumed for velocity field components in the zone 4 :

$v_{z}=-\frac{v_{0}}{h_{t}} z \quad v_{\theta}=-\frac{v_{0}}{h_{t}} \frac{\alpha-\beta}{\beta} r \theta \quad v_{r}=\frac{v_{0}}{h_{t}} \frac{\alpha}{2 \beta} \frac{r^{2}-r_{n}^{2}}{r}$

In the zone 5 components are:

$$
v_{z}=0 \quad v_{\theta}=-\frac{v_{0}}{h_{t}} \frac{\alpha}{2 \beta} \frac{r_{0}^{2}-r_{n}^{2}}{r_{0}} \theta \quad v_{r}=\frac{v_{0}}{h_{t}} \frac{\alpha}{2 \beta} \frac{r_{0}^{2}-r_{n}^{2}}{r_{0}}
$$
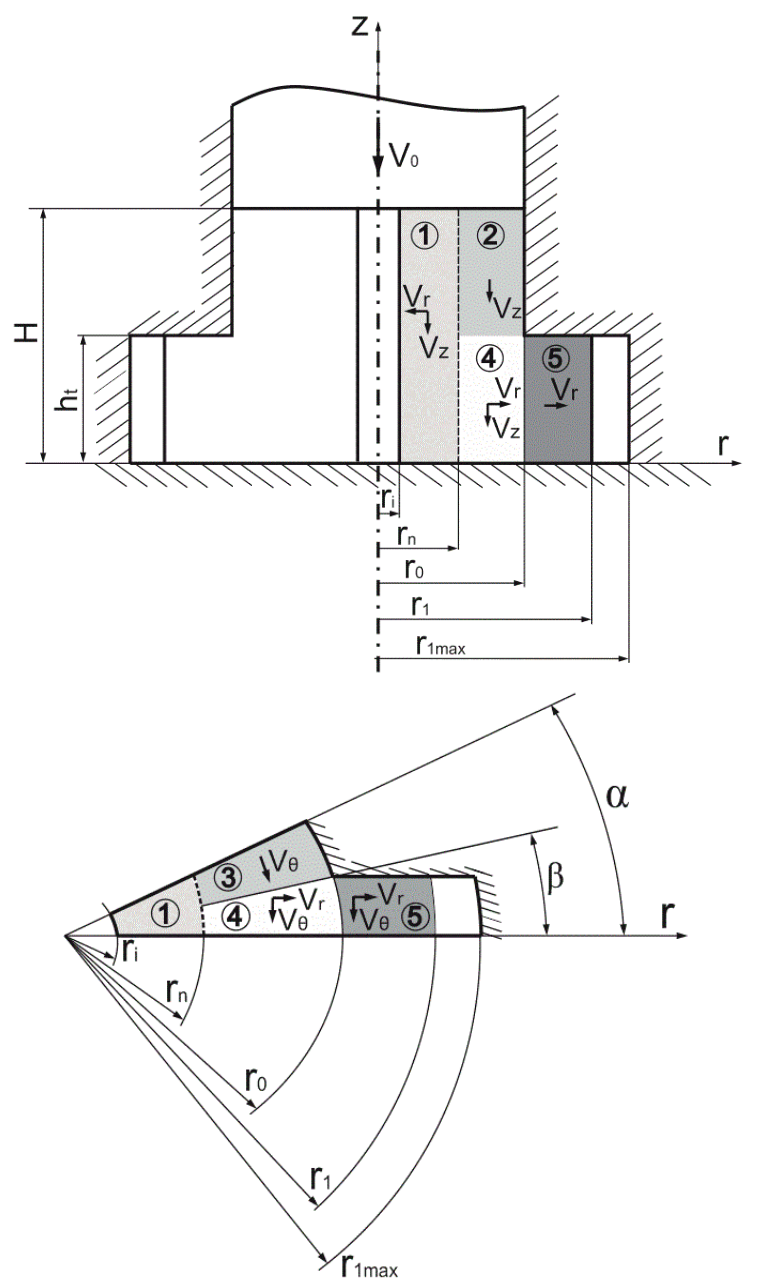

Figure 4 Zones for the $\mathrm{OB}$ model

Forming zones for the OP model were obtained from the model OB by adding two additional zones (zones 6 and 7 in Fig. 5). In these expressions there is an additional variable, $r_{i 0}$, the radius of the central opening in the punch.

For the zone 6, the components are:

$v_{z}=\frac{v_{0}}{H} \frac{r_{n}^{2}-r_{i 0}^{2}}{r_{i 0}^{2}} z \quad v_{r}=-\frac{v_{0}}{2 H} \frac{r_{n}^{2}-r_{i 0}^{2}}{r_{i 0}^{2}} r \quad v_{\theta}=0$

In the zone 7 there is no deformation of the material, and it moves as a rigid body. The components are:

$v_{z}=v_{t} v_{r}=0 \quad v_{\theta}=0$

From the predicted velocity field, strain rate components were derived and using Eq. (1) total power of deformation was determined. The first component, i.e., the power of internal deformation, was determined for each of 
5 zones for the OB model, or 7 zones for the OP model. In zone 2 and zone 7, this component is always zero because the material moves as a rigid body and deformation does not take place. The second component represents shear losses over the surfaces between the zones where velocity discontinuities occur and was calculated as:

$\dot{W}_{s}=\int_{A_{s}} \tau_{s}|\Delta v| d A_{s}=\int_{A_{s}} \frac{\sigma_{e}}{\sqrt{3}}|\Delta v| d A_{s}$

This component for the OB model was determined over 7 surfaces, and for the OP model over 9 surfaces.
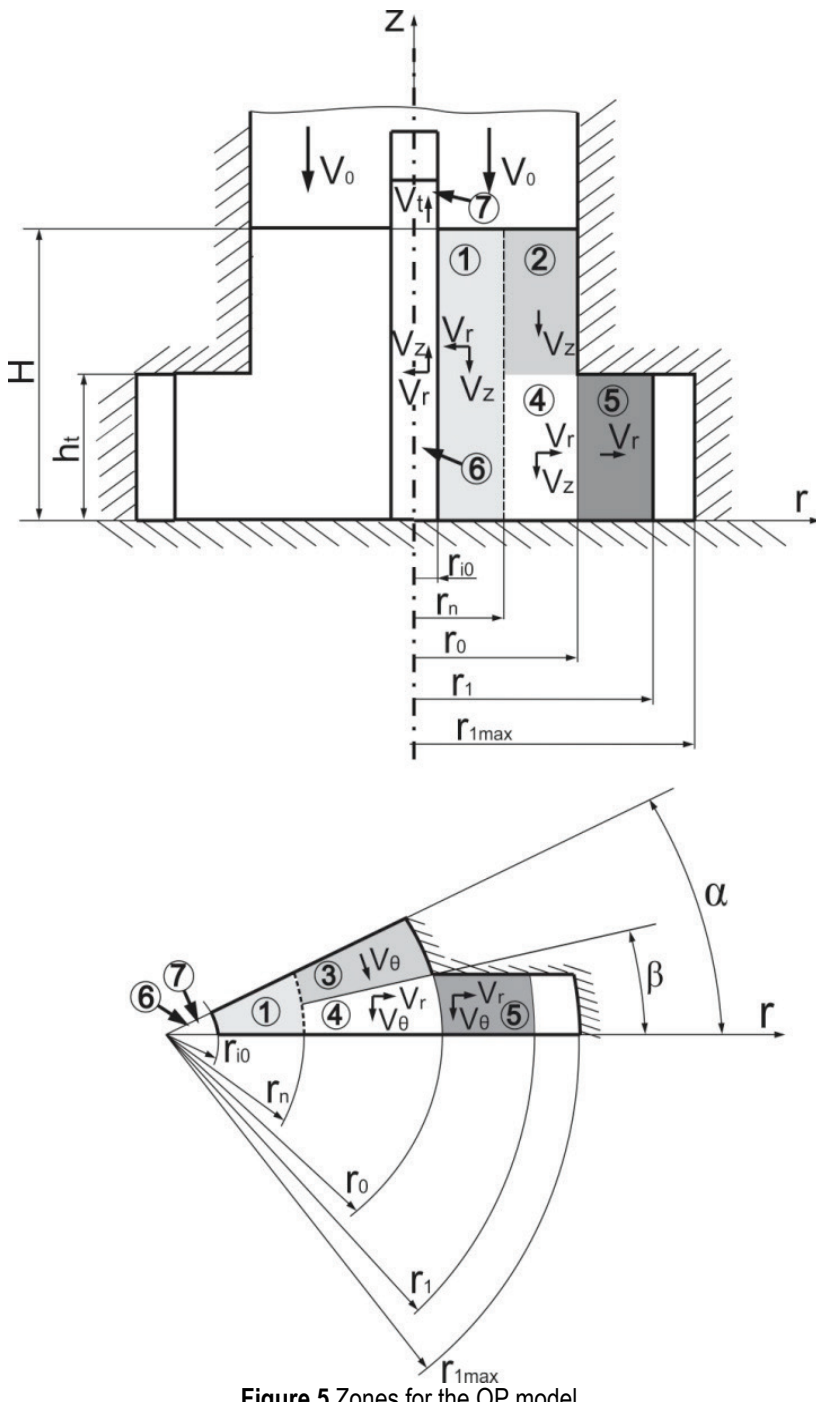

Figure 5 Zones for the OP mode

Last component of the total power of deformation, friction loss was determined from the following expression:

$\dot{W}_{f}=\int_{A_{f}} \tau_{f}|\Delta v| d A_{f}=\int_{A_{f}} \mu \sigma_{e}|\Delta v| d A_{f}$

This component was calculated over contact surfaces between the tool and the material where velocity discontinuities occur. It was assumed that friction obeys the Coulomb's law.

When all components and total power of deformation were determined, the forming load was calculated as:
$F=\dot{W} / v_{0}$

Application of the Upper bound theorem enables good estimation of the forming load for the analysed process which is always valuable in any metal forming process design.

It is important to note that the neutral surface changes its position during extrusion process and different cases of material flow can occur. Several positions of neutral surface with the corresponding values of neutral radius, $r_{n}$, were assumed:

- Radius of neutral surface, $r_{n}$, is between the radius of cylindrical part of workpiece, $r_{0}$, and the radius of flow relief opening $r_{i}$. This is the general case of material flow;

- Neutral surface coincides with the opening surface, $r_{n}$ $=r_{i}$;

- Neutral surface coincides with the surface of cylindrical part of workpiece, $r_{0}$, i.e., $r_{n}=r_{0}$. This case of material flow occurs also when teeth are formed before the opening is filled with material, $r_{1}=r_{1 \max }$;

- The opening is filled with material before teeth are formed, $r_{i} \approx 0$. This is the case of conventional radial extrusion.

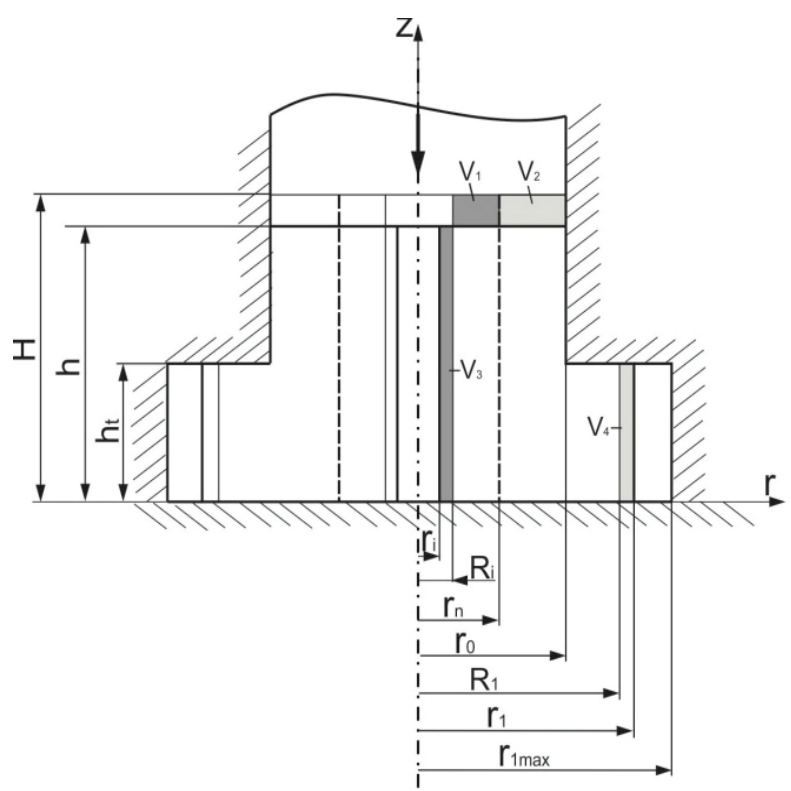

Figure 6 Geometry change, the OB model, general case of material flow

It was assumed that for each punch stroke neutral radius $r_{n}$ maintained a constant value along the entire workpiece height, $H$ and the tooth radius, $r_{1}$ had a constant value along the tooth height $h_{\mathrm{t}}$. To determine relationships between the heights and radii, workpiece volume was divided by neutral surface into two volumes. Position of neutral surface was considered for the general case of material flow, while the volume constancy conditions were applied for both volumes (Fig. 6). One volume constancy condition was applied for the material which flowed towards billet opening and filled it, and the other one was for the material which formed the teeth.

From the first volume constancy relationship between inner radius, $r_{i}$, at the end of the stroke, neutral radius, $r_{n}$ and inner radius at the beginning of the stroke $R_{i}$ was determined (values $H$ and $h$, heights at the beginning and at the end of the stroke, are known values). 
$V_{1}=V_{3}$

$\left(R_{i}^{2}-r_{i}^{2}\right) \pi h=\left(r_{n}^{2}-R_{i}^{2}\right) \pi(H-h)$

$r_{i}=\sqrt{r_{n}^{2}-\left(r_{n}^{2}-R_{i}^{2}\right) \frac{H}{h}}$

From the second volume constancy relationship between outer (teeth) radius, $r_{1}$, at the end of the stroke, neutral radius, $r_{n}$ and outer radius at the beginning of the stroke $R_{1}$ was determined.

$V_{2}=V_{4}$

$\left(r_{0}^{2}-r_{n}^{2}\right) \pi(H-h)=\left(r_{1}^{2}-R_{1}^{2}\right) \beta z h_{t}$

$r_{1}=\sqrt{R_{1}^{2}+\frac{\left(r_{0}^{2}-r_{n}^{2}\right) \pi(H-h)}{\beta z h_{t}}}$

Corresponding relations were derived for the model OP too.

When the total power of deformation is determined for the given geometry and material parameters it becomes a function of tree variables $r_{i}, r_{1}$ and $r_{n}$. The radius of neutral surface $r_{n}$ is determined from the condition that the neutral surface has the position in the workpiece for which the total power of deformation has minimum value. For each punch stroke through several iterations value of $r_{n}$ is determined and then radii $r_{i}$ and $r_{1}$ can be calculated from expressions (5) and (6)

\subsection{Theoretical Results}

The forming load for both models was determined for the following parameters: billet radius $r_{0}=14 \mathrm{~mm}$, outer radius of teeth $r_{\max }=17 \mathrm{~mm}$, angles $\alpha=\pi / 6$ and $\beta=\pi / 12$ (defined at Fig. 1), initial billet height $H_{0}=40 \mathrm{~mm}$, number of teeth $z=6$, teeth height $h_{\mathrm{t}}=15,8 \mathrm{~mm}$, friction coefficient $\mu=0,1$.

Rastegaev method was used for the flow curve determination of $\mathrm{Al}$ 99,5. The flow curve has the following form:

$K=119,39 \cdot \varphi^{0.2048}, \mathrm{MPa}$

This material was also used in the experimental verification of theoretical solution.

The forming load was calculated for two values of billet/punch openings: $5 \mathrm{~mm}$ and $8 \mathrm{~mm}$. The height of punch opening was $15 \mathrm{~mm}$. For the conventional extrusion forming load was also determined using Eq. (4).

For the given parameters, two cases of material flow occurred, i.e., the neutral surface had two positions. At the beginning of the OB process, the general case of material flow occurred $\left(r_{i}<r_{n}<r_{0}\right)$. The material flowed in this way until teeth were completely formed. Forming load -stroke diagram for this part of process as well as for the conventional process is presented in Fig. 7. The diagram is based on the theoretical results which indicate that the required forming loads for $\mathrm{OB}$ processes are lower than that for the conventional process. Also, because of the billet opening, longer punch stroke is required in the $\mathrm{OB}$ process.

At the point of the process where teeth are formed, according to the theoretical solution, the central opening still existed, while the neutral surface coincided with the cylindrical part of workpiece, $r_{0}$. In that case, the material flowed only towards the central opening. This resulted in large increase of forming load (dotted segments of curves in Fig. 8)

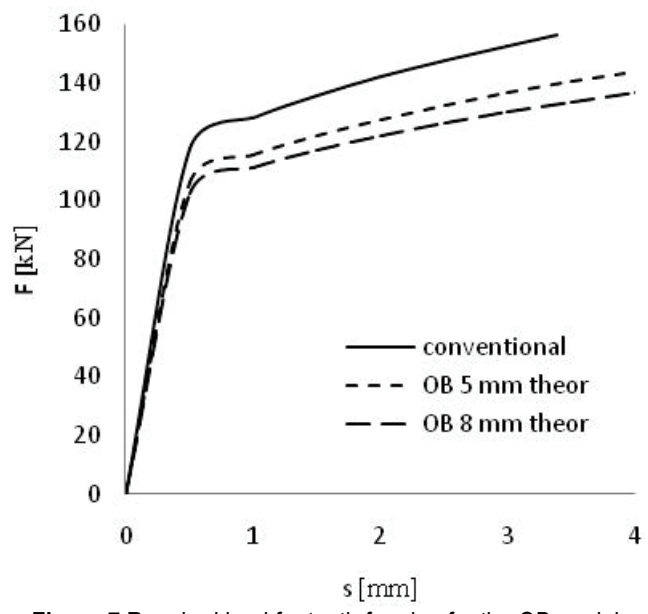

Figure 7 Required load for teeth forming for the OB model

From the load-stroke diagram for the conventional process it can be seen that the predicted simplified way of teeth forming impacts the value of the required forming load, since the final stage of the process is left unaccounted for (there is no load rise at the end of the process).

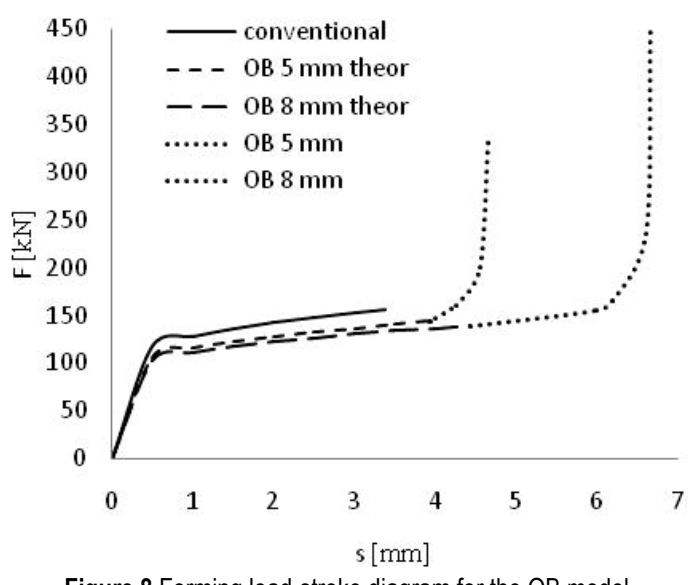

Figure 8 Forming load-stroke diagram for the OB model

At the beginning of the OP process, the material flowed only towards die cavities where the teeth were formed - the same way as in a conventional process. However, there was a difference in the forming load values (load for conventional process was higher) because the material flowed into the punch opening as the punch moved downwards (Fig. 9). Because the volume of the punch opening was smaller than that of the billet opening, the difference between punch stroke of the conventional and the OP process became smaller.

Once the teeth were completely formed in the OP process, the material filled the remaining empty volume of punch opening causing substantial increase of forming load. This part of the process corresponds to the dotted 
segments of curves in the diagram in Fig. 10. Comparing the diagrams in Fig. 8 and Fig. 10, it can be seen that, according to theoretical solution, there is a difference in the load values at the final stage of the $\mathrm{OB}$ and OP processes. The increase of the opening diameter in the billet requires higher forming load at the final stage of the process, when the opening is completely filled with material, while in the OP process, increased opening in the punch lowered the forming load at the end of the process, when the punch was filled with the material.

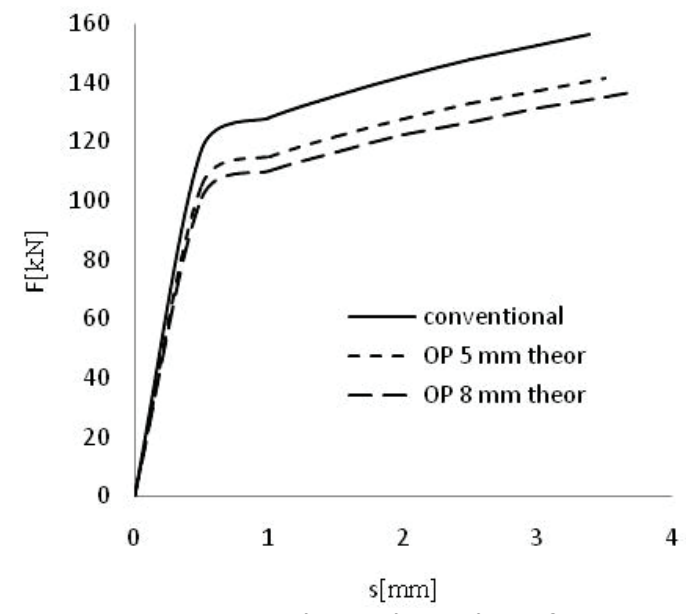

Figure 9 Required load-for teeth forming for the OP model

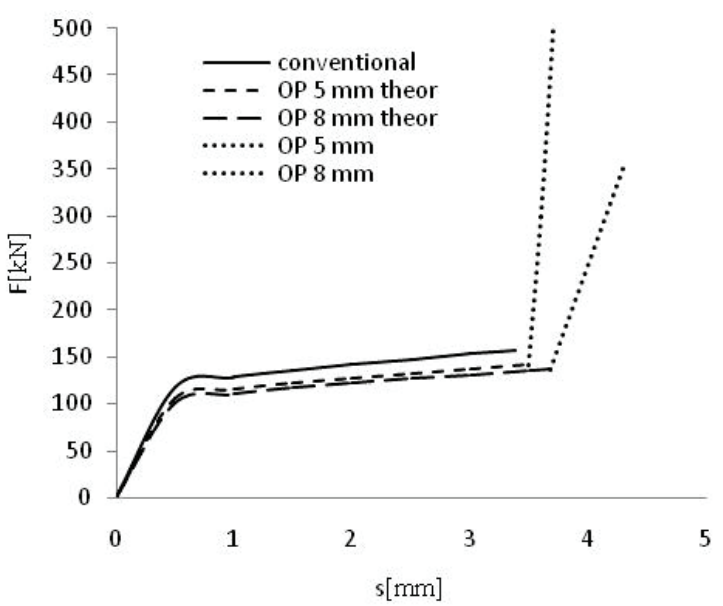

Figure 10 Forming load-stroke diagram for model OP - complete process

\section{EXPERIMENT}

Experiment was conducted in order to verify theoretical solution. The tooling used in the experiment for the OP process is presented in Fig. 11. As can be seen from the figure, the replaceable punch insert was used so that the experiment for different diameters of punch opening could be conducted without dismantling. The die was made with replaceable insert to enable extrusion of different tooth shapes. Punch and die inserts are presented in Fig. 12. The same tooling without punch insert was used for the OB process. Instead of solid billets, the billets with central opening were used (Fig. 13). Conventional extrusion experiment was conducted without die and punch inserts and with a solid billet.

The value of friction coefficient $(\mu=0,1)$ was determined by ring compression test. Billet and tool were lubricated with mineral oil.
Experiments were carried out on Sack \& Kiesselbach hydraulic press $6,3 \mathrm{MN}$ with punch velocity of $1 \mathrm{~mm} / \mathrm{s}$ at room temperature.

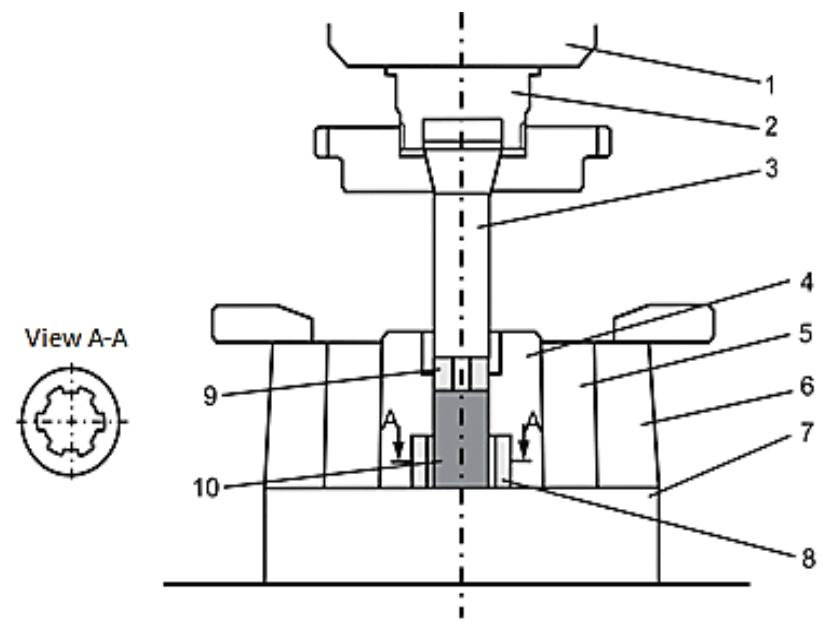

Figure 11 Experimental tooling for model OP:1 Upper plate, 2 Punch holder, 3 Punch, 4 Die, 5 Inner ring, 6 Outer ring, 7 Lower plate, 8 Replaceable die insert, 9 Replaceable punch insert, 10 Billet

Eight-channel amplifier Spider 8 (Hottinger Baldwin Messtechnik GmbH (HBM), Germany) was used to measure the forming load and punch stroke. Adequate transducers were applied (pressure transducer P3M 500 bar, displacement transducer $\mathrm{W} 20 \pm 50 \mathrm{~mm}$ ) using the Catman Easy software.

Extruded parts from both types of the process are presented in Fig. 14.

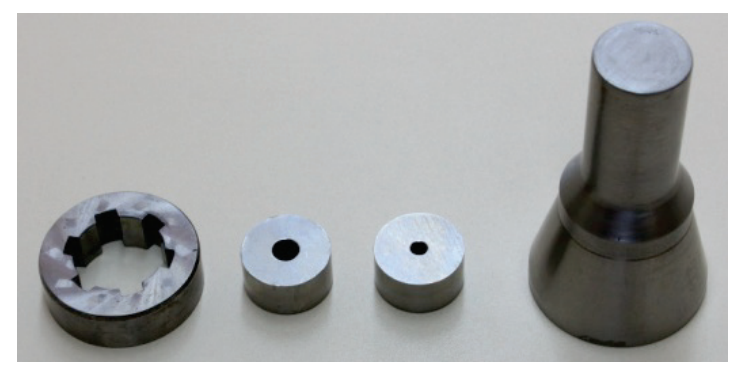

Figure 12 Replaceable die and punch inserts with punch

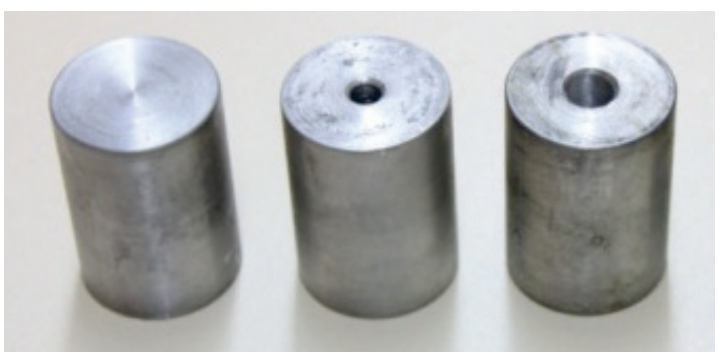

Figure 13 Solid billet and billets with central opening

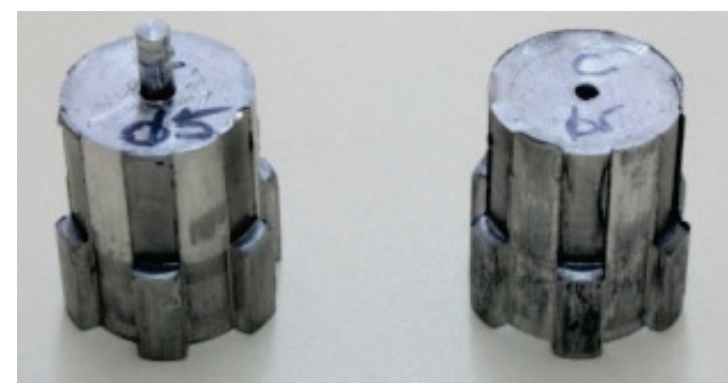

Figure 14 Extruded parts 


\section{RESULTS AND DISCUSSION}

According to the theoretical solution, for the given parameters in the OB process, two cases of material flow occurred. At the first stage of the process, teeth were formed, and material filled both the die cavity and the relief opening. At that stage of the process the experimentally obtained load values showed good agreement with the theoretical prediction, as can be seen in Fig. 15 which represents comparison of theoretical and experimental results for the model $\mathrm{OB}$ with $5 \mathrm{~mm}$ central opening in the billet. Although the agreement between experimental and theoretical results indicates that the theoretical solution adequately describes the process, due to the characteristic of the Upper bound method, the expected theoretical values could have been higher than the experimental ones.

Certain difference in the stroke and load values were observed at the end of the process when teeth's forming was completed and the material flowed only towards the central opening. This can be explained by the elastic deformation of the tooling and press which was not taken into account in the theoretical solution.

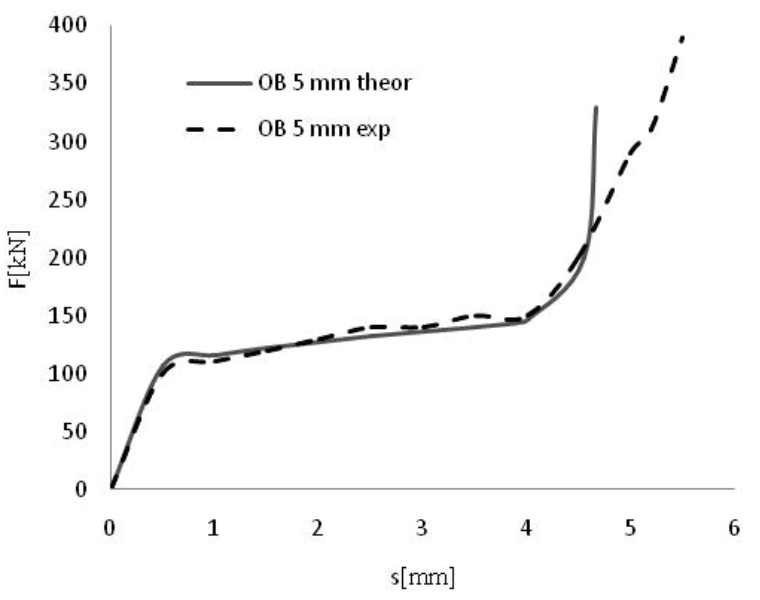

Figure 15 Load-stroke diagram for model $\mathrm{OB}$ with $5 \mathrm{~mm}$ billet opening

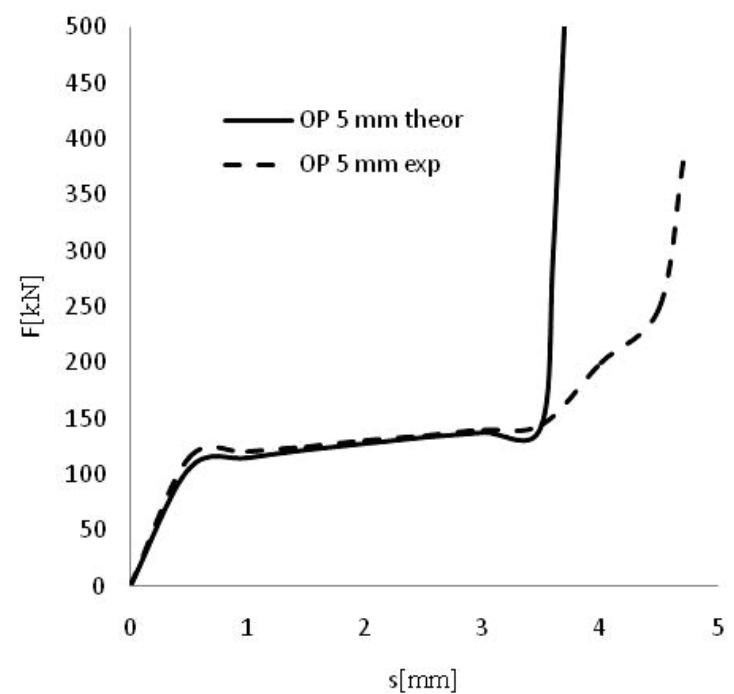

Figure 16 Load-stroke diagram for model OP with $5 \mathrm{~mm}$ punch opening

In the model OP, the neutral surface also had two different positions during extrusion process. At the first stage of the process, just like the OB process, the teeth were formed, but the position of neutral surface was constant.
For this stage of the process there was a good agreement between predicted and experimentally obtained values (same as for the OB model). The influence of elastic deformation of the forming system is also evident, at the end of the process, due to disagreement between the theoretical and experimental punch strokes (Fig. 16). In this case, the maximum load for punch opening filling is lower than the theoretically predicted value.

Both theoretical and experimental results showed that application of both deformation models resulted in the reduction of the required forming load at the teeth-forming process stage.

Relatively large elastic deformation of the forming system influenced the accuracy and quality of extruded parts. The difference between experimental and theoretical punch strokes indicated that improvement of the forming system is necessary to reduce high impact of elastic deformation.

However, more accurate information and better understanding of both processes requires the extrusion experiment to be performed in stages. That should result in additional information about the forming load change and material flow during process. Information about material flow is very important especially because the radii of the tooth surface and inner surface of the billet with central opening are not constant over the entire height, as opposed to the theoretical assumption. A better insight into the material flow during extrusion process would help not only to better define the existing components of velocity field, but would also enable the addition of new components of the velocity field in the zones where the outer surface of the teeth and inner surface of the billet opening are formed. These surfaces are not cylindrical because of the friction influence.

\section{CONCLUSION}

Application of flow relief openings in extrusion process enables divided material flow, which, in turn, reduces the forming load. This principle is often applied in the gear and spline production. Implementation of flow relief opening has so far been analysed in the context of forging or extrusion of numerous types of gears and splines. Most solutions employed some sort of relief opening in the billet. Considering the upper bound method application, each tooth shape demands specification of its own velocity field in order to define the adequate forming load.

This study was focused on the application of flow relief opening in radial extrusion of a gear-like element with straight parallel flank profile, which is a type of element rarely analysed from the aspect of divided material flow. Two positions of relief openings were analysed: relief opening in the centre of the billet (model OB), and relief opening in the centre of the punch (model OP). The Upper bound theorem was applied to theoretically analyse the processes. As a result, forming load was determined for both deformation models.

The forming loads obtained for both models by theoretical solution were compared with experimental results.

This comparison showed that application of both deformation models resulted in the forming load reduction 
at the teeth formation process stage. Comparison between the theoretically predicted load and the experimentally obtained values showed satisfactory agreement.

However, the accuracy and quality of extruded parts have not been satisfactory due to the relatively large elastic deformation of the forming system, which indicates the need for tooling improvement.

Extrusion experiment should be conducted in stages, which will provide better insight into forming load changes and material flows, especially in the context of variable workpiece surfaces.

Theoretical solution can be further improved by introducing additional forming zones which would take into account corner filling of the die, yielding a more realistic prediction of material flow. It could be also improved by introducing two values of neutral radius $r_{\mathrm{n}}$, in the cylindrical zone and in the geared zone of the billet, which would contribute to a more realistic representation of material flow.

These results indicate that further improvement of theoretical solution and extrusion experiment is possible and necessary in order to better describe material flow during forming process and obtain more accurate load values.

\section{REFERENCES}

[1] Ogha, K. \& Kondo, K. (1982). Research on the precision die forging utilizing divided flow (First report, theoretical analysis of process utilizing flow relief-axis and flow relief hole). Bulletin of the JSME, 25(209), 1828-1835. https://doi.org/10.1299/jsme1958.25.1828

[2] Ogha, K., Kondo, K., \& Jitsunari, T. (1982). Research on the precision die forging utilizing divided flow (Second report, Experimental study of processes utilizing flow relief-axis and flow relief hole). Bulletin of the JSME, 25(209), 18361842. https://doi.org/10.1299/jsme1958.25.1836

[3] Ogha, K., Muragoshi, F., Ando, H., \& Kondo, K. (1996). Precision cold die forging of actual steel gear toothed products utilizing divide flow. Proceeding of $5^{\text {th }}$ Int. Conference on Technology of Plasticity / Ohio, USA, 331339.

[4] Kondo, K., Ikushima, K., Inoshita, H., Ogura, M., \& Ono, K. (2002). Net shape forging of an external helical gear with boss and internal spline. Proceedings of the $7^{\text {th }}$ Int. Conference on Technology of Plasticity / Yokohama, Japan, 49-54.

[5] Feng, W., Hua, L., \& Han, X. (2012). Finite element analysis and simulation for cold precision forging of a helical gear. Journal of Central South University of Technology, 19(12), 3369-3377. https://doi.org/10.1007/s11771-012-1416-4

[6] Choi, J. C. \& Choi, Y. (1999). Precision forging of spur gears with inside relief. International Journal of Machine Tools \& Manufacture, 39(10), 1575-1588. https://doi.org/10.1016/S0890-6955(99)00015-2

[7] Choi, J., Cho, H., \& Jo, C. (2000). An upper bound analysis for the forging of spur gears. Journal of Materials Processing Technology, 104, 67-73. https://doi.org/10.1016/S0924-0136(00)00524-0

[8] Choi, J., Cho, H., \& Choi, J. (2000). Upper bound analysis for forging of trochoidal gears. Journal of Materials Processing Technology, 103, 347-352. https://doi.org/10.1016/S0924-0136(00)00481-7

[9] Hu, C., Wang, K., \& Liu, Q. (2007). Study on a new technological scheme for cold forging of spur gears. Journal of Materials Processing Technology, 187-188, 600-603. https://doi.org/10.1016/j.jmatprotec.2006.11.037
[10] Cai, J., Dean, T. A., \& Hu, Z. M. (2004). Alternative die design in net-shape forging of gears. Journal of Materials Processing Technology, 150(1-2), 48-55. https://doi.org/10.1016/j.jmatprotec.2004.01.019

[11] Politis, D. J., Dean, T. A., \& Balint, D. S. (2014). An investigation into the forging of Bi-metal gears. Journal of Materials Processing Technology, 214, 2248-2260. https://doi.org/10.1016/j.jmatprotec.2014.04.020

[12] Zuo, B., Wang, B., Li, Z., Zheng, M., \& Zhu, X. (2015). Design of relief-caviti in closed-precision forging of gears. Journal of Central South University of Technology, 22(4), 1287-1297. https://doi.org/10.1007/s11771-015-2645-0

[13] Behrens, B. A., Bouguecha, A., Klassen, A., Schäfer, F., Bistron, M., Dähndel, H., \& Odening, D. (2010). Anforderungen an Umformwerkzeuge für das gratlose Präzisionsschmieden. Proceedings of 2. AutoMetForm - 17. Sächische Fachtagung Umformtechnik Tagungsband / Freiberg, Germany, 299-311.

[14] Behrens B.-A., et al. 2014. Near-Net and Net Shape Forging. Comprehensive materials processing, Vol. 3, Amsterdam: Elsevier, 427-446. https://doi.org/10.1016/B978-0-08-096532-1.00323-X

\section{Contact information:}

Plavka SKAKUN, Assistant Professor

University of Novi Sad, Faculty of Technical Sciences,

Trg Dositeja Obradovića 6, 21000 Novi Sad, Serbia

E-mail: plavkas@uns.ac.rs

Robert LENGYEL, PhD student

University of Novi Sad, Faculty of Technical Sciences,

Trg Dositeja Obradovića 6, 21000 Novi Sad, Serbia

E-mail: lengyelrobi@hotmail.com

Sebastian BALOŠ, Associate Professor

University of Novi Sad, Faculty of Technical Sciences,

Trg Dositeja Obradovića 6, 21000 Novi Sad, Serbia

E-mail: sebab@uns.ac.rs

Dejan MOVRIN, Teaching and Research Assistant University of Novi Sad, Faculty of Technical Sciences, Trg Dositeja Obradovića 6, 21000 Novi Sad, Serbia E-mail: movrin@uns.ac.rs

Mladomir MILUTINOVIĆ, Assistant Professor University of Novi Sad, Faculty of Technical Sciences, Trg Dositeja Obradovića 6, 21000 Novi Sad, Serbia E-mail: mladomil@uns.ac.rs 